\title{
Congrès national de la Société espagnole de médecine et chirurgie du pied et première réunion hispanofrançaise, Séville, 8 et 9 avril 2010
}

\section{National Conference of the Spanish Society for Medicine and Surgery of the Foot and first Franco-Hispanic Meeting, Seville 8th and 9th April 2010}

\section{P.-H. Benamou, P. Jouet}

(C) Springer-Verlag 2010

La Société française de médecine et chirurgie du pied a participé à cette Première réunion hispanofrançaise et a présenté les communications suivantes :

- Nuevas ideas en materia de talalgias : síndromes. de compresión nerviosa (M. Bouysset).

- Talagiias del niño (C. Themar Noël, G. Rougereau).

- Tratamiento medico y fisioterapia en talalgias debidas a compresión nerviosa (P. Jouet).

- Tratamiento quirúrgicotras compresión de los nervios.

- Pedios en pacientes con talalgia (P. Diebold, G. Rougereau).

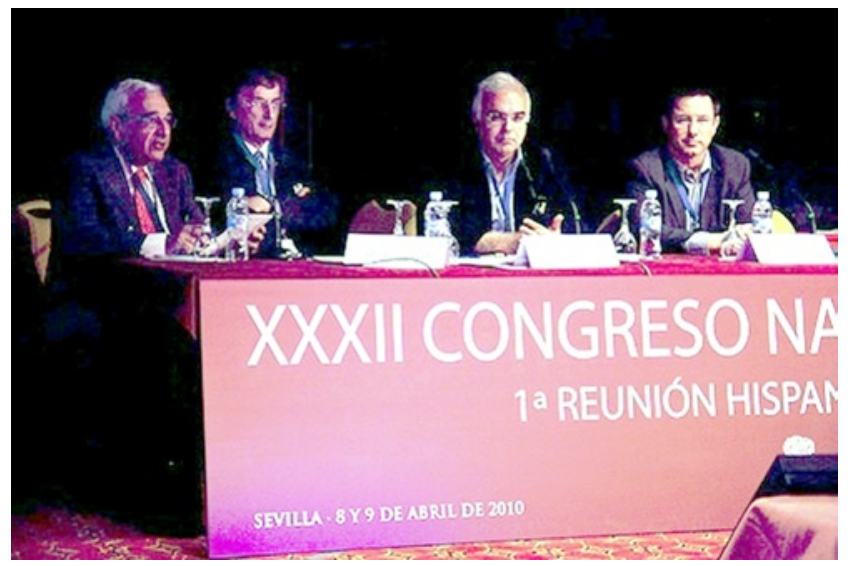

Dr A. Carranza-Bencamo (Séville), président du congrès Dr M. Bouysset (Lyon), vice-président de la SFMCP Dr G. Rougereau (Paris), président de la SFMCP Dr P. Jouet (Bayonne), secrétaire de la SFMCP

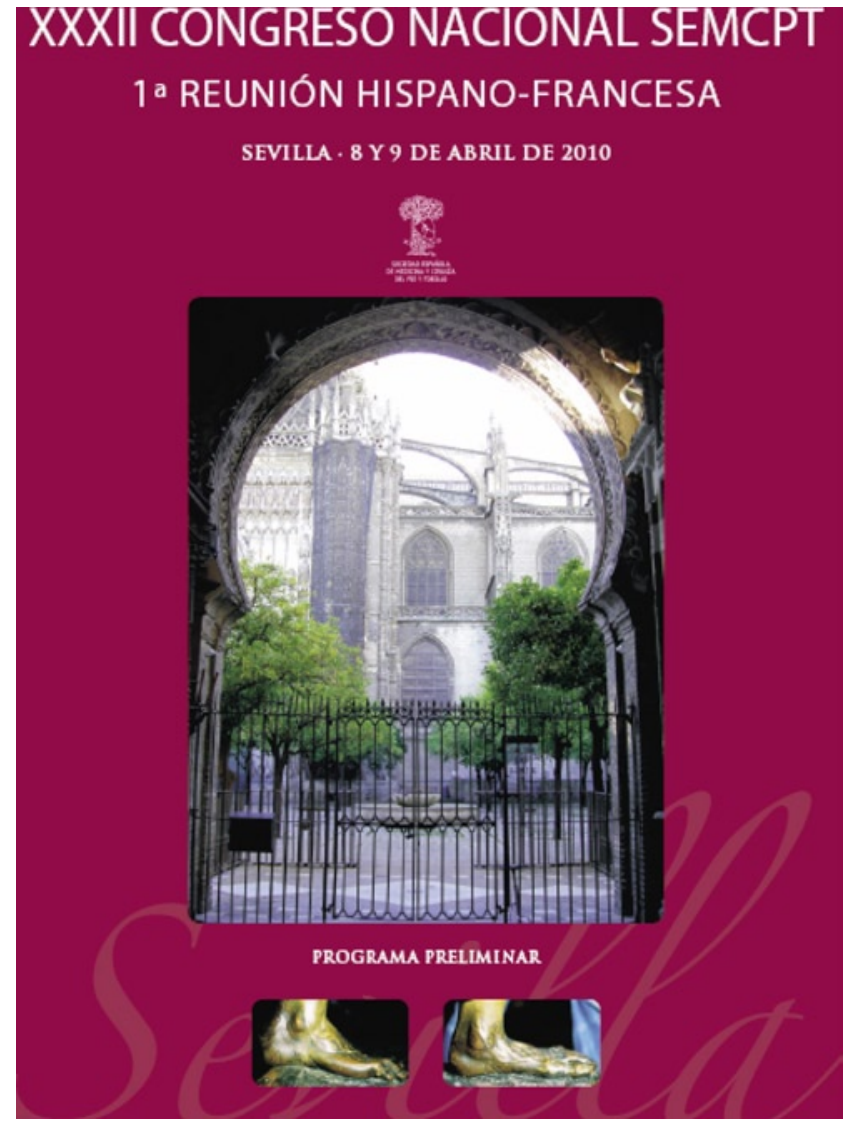

